\title{
Primary orbital melanoma masquerading as vascular anomalies
}

\begin{abstract}
Purpose To review two cases of primary orbital melanoma presenting like orbital vascular anomalies.

Methods Retrospective review of clinical presentation, treatment, radiology and pathology for two patients under the care of the Orbital Clinic at Moorfields Eye Hospital.

Results Both lesions presented with the appearance and behaviour of vascular anomalies. In one case, a spindle cell melanoma appeared to be a low flow vascular anomaly with a loculated secondary haemorrhage and, in the other case, a melanoma of soft parts was considered to be an arteriovenous malformation and responded partially to embolisation. Conclusion Primary malignant melanoma may present as a secondary vascular lesion of the orbit and this very rare tumour should be considered in the differential diagnosis of any vascular anomaly.

Eye (2002) 16, 16-20. DOI: 10.1038/

$\mathrm{sj} / \mathrm{EYE} / 6700025$
\end{abstract}

Keywords: orbit; melanoma; vascular anomaly; arteriovenous malformation

\section{Introduction}

${ }^{1}$ Moorfields Eye Hospital London, UK

${ }^{2}$ Department of Pathology Institute of Ophthalmology London, UK

Correspondence: GE Rose, MS FRCOphth Orbital Clinic

Moorfields Eye Hospital City Road London EC1V 2PD, UK E-mail: geoff.rose@ moorfields.nhs.uk
Primary orbital melanoma is extremely rare, but has been reported to arise in association with naevus of Ota, blue cellular naevus and oculodermal melancytosis. Although no characteristic presentation has been described, most patients present with proptosis and the diagnosis is established on biopsy. We describe two cases of orbital melanoma (of which one was a melanoma of soft parts) presenting with the appearance and natural history of orbital vascular anomaliesa presentation that, as far as we are aware, has not been previously reported.
V Lee ${ }^{1}$, C Sandy ${ }^{1}$, GE Rose ${ }^{1}$, IM Moseley ${ }^{1}$, I Cree $^{2}$ and JL Hungerford ${ }^{1}$
Patients with primary orbital melanoma were identified from the orbital database at Moorfields Eye Hospital and a retrospective case-note review of clinical, radiological and pathological details was performed.

Results

Case 1

A 49-year-old white woman was referred with a one month history of a pink subconjunctival mass lying in the inferotemporal conjunctiva of the left orbit (Figure 1a), this mass having large surface feeder vessels with a flow of 15 $\mathrm{m} / \mathrm{s}$ (colour-coded Doppler ultrasonography). Ipsilateral melanosis of the infero-nasal sclera had been present since birth and fundus examination and B-mode ultrasonography of the globe was normal. A diagnosis of lowflow orbital vascular anomaly was made, this being supported by contrast enhanced axial CT (Figure 1b). Ten months later the patient developed a red eye and diplopia, due to acute haemorrhage from the lesion and, as symptoms failed to resolve, the mass was explored and found to be lying on, but not arising from, the infero-temporal sclera of the left globe (Figure 1c). The tumour was found to be widely infiltrating orbital fat, the inferior oblique muscle and the inferior and lateral recti and composed a cellular partlypigmented mass with islands of polygonal and spindle cells, which were clearly pigmented, of melanocytic origin and displaying mild nuclear polymorphism with scanty mitoses. There was histological evidence of infiltration of skeletal muscle and fibrofatty tissue but no vascular invasion. Systemic evaluation failed to show systemic disease and the patient underwent further debulking of the tumour prior to receiving orbital radiotherapy. Two years later, she has 
a

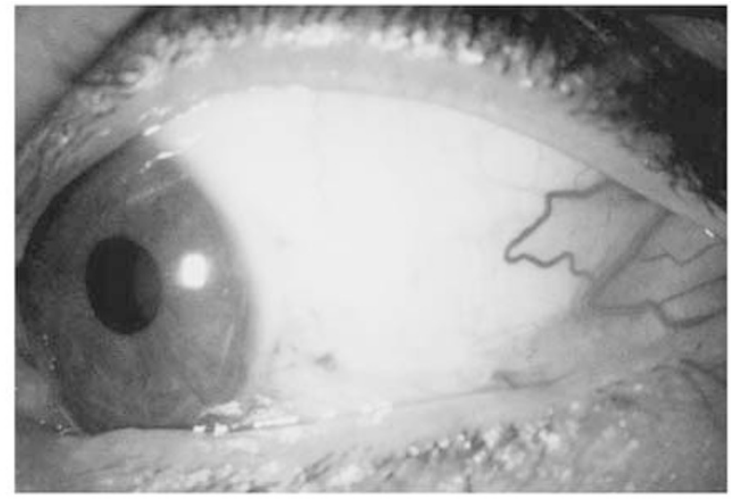

b

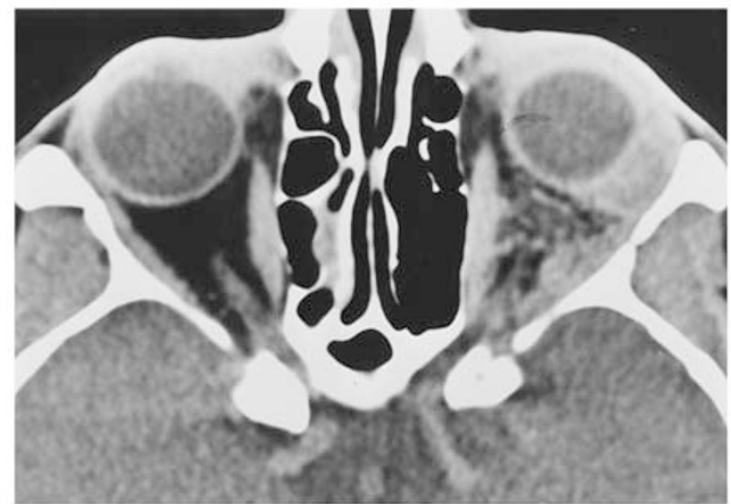

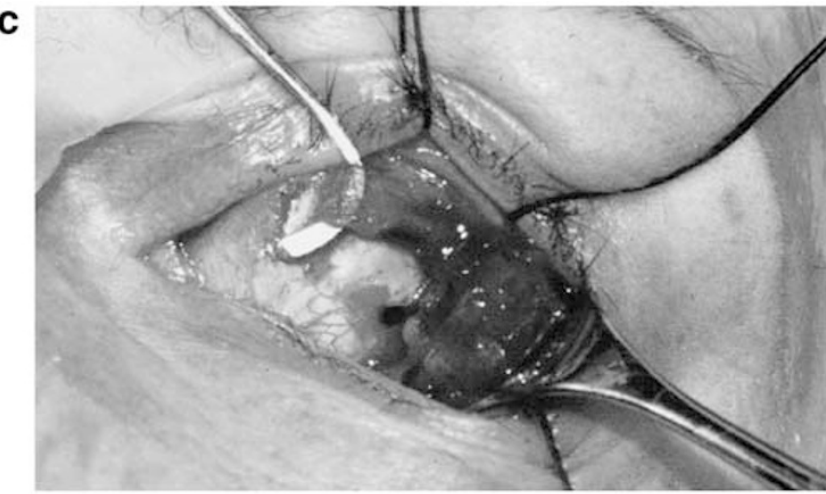

Figure 1 (Case 1). (a) Prominent vessels on a pink subconjunctival mass in infero-temporal quadrant of the left orbit conjunctiva with prominent feeding vessels. (b) Contrast-enhanced axial CT. (c) Transconjunctival orbitotomy revealed a dark mass lying on, but not apparently arising from, the infero-temporal sclera of the left globe.

global restriction of eye movements, but with no clinical evidence of growth of the residual mass.

\section{Case 2}

After presenting with an increasing, painless left lower lid mass, a 30-year-old white male was referred to the Orbital Clinic and found to have a Snellen acuity of $6 / 6$ with normal intraocular examination. There was a large infero-temporal purple mass with overlying dilated tortuous blood vessels (Figure 2a), this mass blanching on digital pressure, but showing no variation with the Vasalva manoeuvre. Colour-coded Doppler ultrasonography demonstrated a highly vascular lesion, with many vessels showing arterial waveforms.

Ultrasonography, radiology and clinical examination being compatible with orbital arteriovenous malformation (AVM), the patient underwent angiography with superselective catheterisation of the infraorbital artery and embolisation of several feeder arteries to the posterior and inferior aspects of the lesion (Figure 2b). When the swelling increased again after 6 months, the mass-appearing to originate from fascia between the inferior rectus and inferior oblique muscles-was resected intact (Figure 2c).

Histopathology showed a well-circumscribed tumour, almost entirely surrounded by a fibrous pseudocapsule, with cells that were separated into small groups with many large vascular spaces. The tumour cells were of medium-size, displayed nuclear pleomorphism and prominent nucleoli with few mitoses, and had either vacuolated (clear cell) or granular cytoplasm, the granules not staining with periodic acid Schiff (PAS). There were no crystalline inclusions (characteristic of alveolar soft part sarcoma) and immunohistochemistry was negative for epithelial markers and factor VIII, weakly positive for S-100, and strongly positive for HMB45 (Figure 2d) -this pattern being in keeping with melanoma of soft parts (otherwise known as clear cell sarcoma).

The patient remained well for the 4 years before developing a recurrent left lower lid mass, associated with visual deterioration to $6 / 36$. A firm vascular lesion, infiltrating orbital fat, was resected from the orbital rim and the histology found to be identical to that of the previous tumour. The patient underwent orbital radiotherapy, with local recurrence a year later, for which he is receiving systemic chemotherapy. 
a

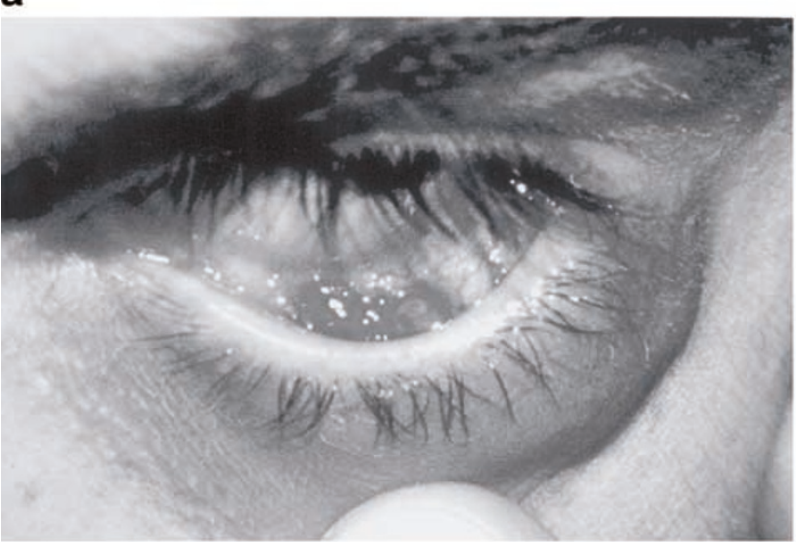

b

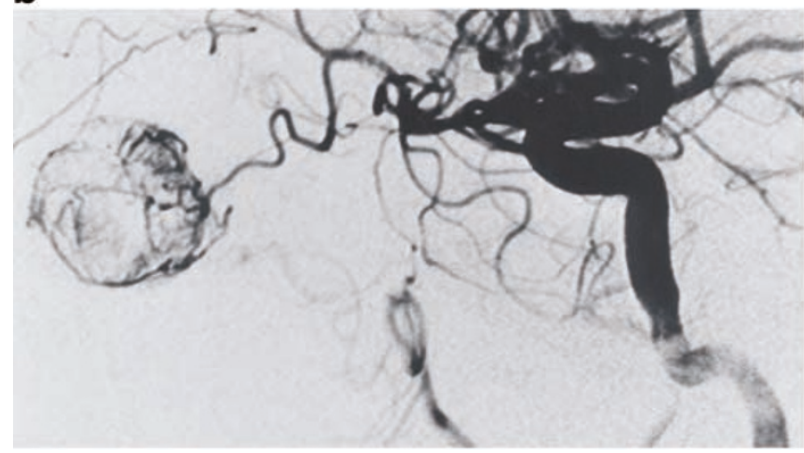

C

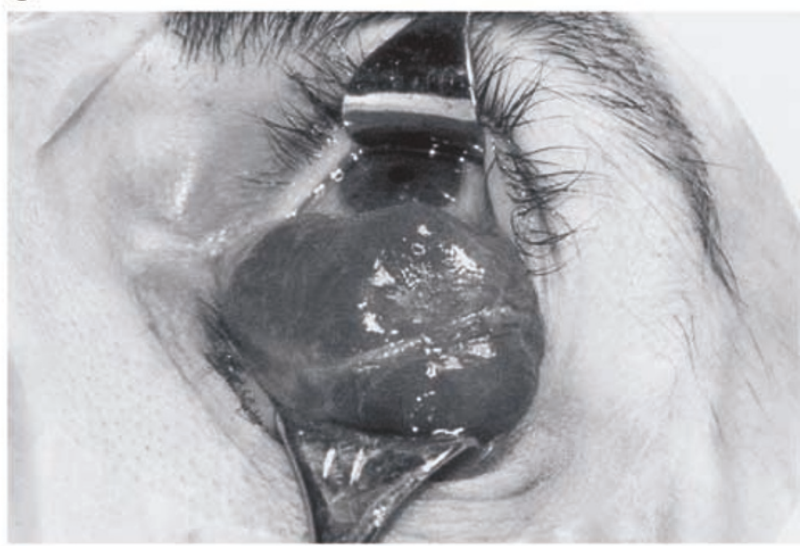

d

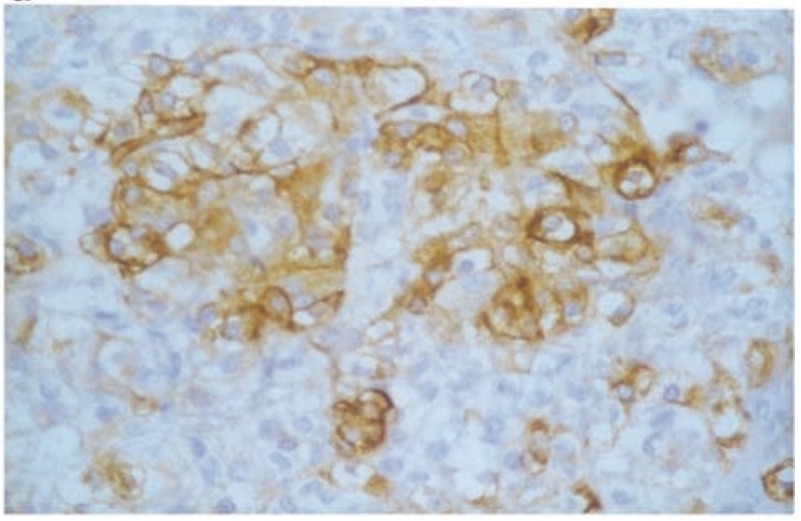

Figure 2 (Case 2) (a) Presenting large, highly-vascular purple mass in inferotemporal fornix. (b) Left internal carotid angiogram, lateral projection (with some reflux into external carotid): tortuous branches of the ophthalmic artery supply a rounded, hypervascular mass. There was also supply from the infraorbital branches of the external carotid. (c) At surgery, via a lower lid swinging flap, the mass appeared to originate from the capsulopalpebral fascia near the inferior rectus and inferior oblique muscles. (d) Tumour cells strongly staining with antibody HMB45 $(\times 400)$.

\section{Discussion}

Due to their rarity, orbital melanomas have been described as pathological curios and constitute less than $1 \%$ of orbital neoplasms. ${ }^{1}$ Histologically these tumours resemble uveal melanomas ${ }^{2}$ and, in the largest series reported, $90 \%$ were associated with blue naevus and $48 \%$ had pre-existing melanosis. ${ }^{3}$ Jacobiec $^{4}$ proposed that persistence of 'atavistic dermal melanocytes' from the embryological neural crest migration give rise to melanomas in the orbit, an area which is normally free from melanocytes.

'Melanoma of soft parts' (MMSP) is also known as clear cell sarcoma, due to its usual association with tenosynovial structures and the typical histological appearance of variable-sized nests of uniform plump spindle cells-with clear cytoplasm separated by fibrous septa. ${ }^{5}$ There is no racial predilection, they tend to occur in young people, and there is a female preponderance. ${ }^{6-8}$ Immunophenotypical and ultrastructural studies have shown that this tumour is derived from neuroectoderm and shows positive reactivity with melanoma specific antigens, HMB45 and S-100. Ninety-five percent of MMSPs present in the upper and lower extremities, with only $1.9 \%$ occurring in the head and neck region; the MMSP in Case 2 arose from the capsulopalpebral fascia of the inferior rectus and inferior oblique, a feature which has never been previously reported. One review of reports found that two-thirds of patients had disease recurrence within 49 months post diagnosis, with a $50 \%$ mortality over this period ${ }^{7}$-although local recurrence, satellite lesions or nodal metastasis were not uniformly fatal. ${ }^{8}$ Survival has been correlated to tumour size, tumour necrosis and ploidy status ${ }^{9}$ and neither chemotherapy nor radiotherapy has been shown to increase survival. ${ }^{6}$

The natural history of orbital melanoma is not known and there is no agreed consensus for optimal management (Table 1). Most patients present with increasing proptosis and our two cases are unique in masquerading as vascular anomalies. Radiological 


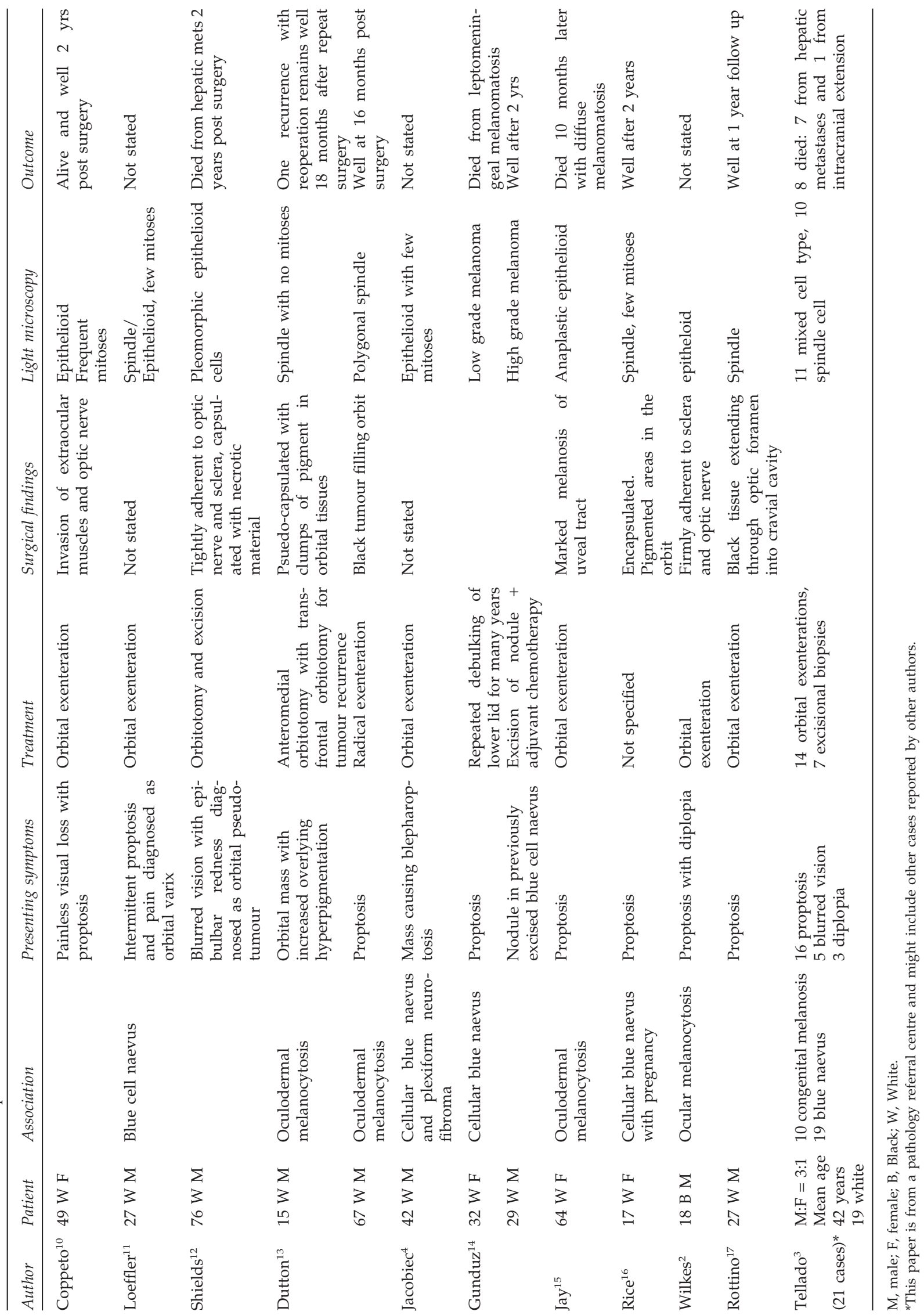


diagnosis of melanoma is generally straightforward when the lesion is intraocular, as CT, MRI and ultrasonography are characteristic. An orbital mass involving the eye, which can occur in a variety of inflammatory or malignant conditions, usually proves to have arisen within the eye and extended outwards; when associated with a phthisical globe, choroidal melanoma should be assumed until proven otherwise.

\section{Conclusions}

The diagnosis of primary orbital melanoma cannot be made on imaging and, in both cases described here, the presenting anterior orbital mass was suggestive of a vascular lesion. Given the rarity of primary orbital melanoma, in comparison with vascular lesions, we would recommend that biopsy should continue to be reserved for atypical lesions.

\section{Acknowledgements}

The authors would like to thank Professor Luthert, Institute of Ophthalmology for his advice.

\section{References}

1 Shields JA, Bakewell B, Augsburger JJ, Flanagan JC. Classification and incidence of space occupying lesions of the orbit. A survey of 645 biopsies. Arch Ophthalmol 1984; 102: 1606-1611.

2 Wilkes TD, Uthman EO, Thornton CN, Cole RE. Malignant melanoma of the orbit in a black patient with ocular melanocytosis. Arch Ophthalmol 1984; 102: 904-906.

3 Tellado M, Specht CS, McClean IW, Grossniklaus HE, Zimmermann LE. Primary orbital melanomas. Ophthalmology 1996: 103: 929-932.

4 Jakobiec FA, Ellsworth R, Tannenbaum M. Primary orbital melanoma. Am J Ophthalmol 1974; 78: 24-39.
5 Sara AS, Evans HL, Benjamin RS. Maligant melanoma of soft parts (clear cell sarcoma): a study of seventeen cases with emphasis on prognostic factors. Cancer 1990; 65: 367-374.

6 Eckardt JJ, Pritchard DJ, Soule-EH. Clear cell sarcoma. A clinicopathologic study of 27 cases. Cancer 1983; 52: 14821488.

7 Hicks MJ, Sladivar VA, Chintagumpala MM, Horowitz $\mathrm{ME}$, Cooley LD, Barrish JP et al. Malignant melanoma of soft parts involving the head and neck region: review of the literature and case report. Ultrastruct Pathol 1995; 19: 395-400.

8 Aue G, Hedges LK, Schwartz HS, Bridge JA, Neff JR Butler MG. Clear cell sarcoma or malignant melanoma of soft parts: molecular analysis of microsatellite instability with clinical correlation. Cancer Genet \& Cytogenet 1998; 105: 24-28.

9 Lucas DR, Nascimento AG, Sim FH. Clear cell sarcoma of soft tissues. Mayo Clinic experience with 35 cases. Am J Surg Pathol 1992; 16: 1197-2004.

10 Coppeto JR, Jaffe R, Gillies CG. Primary orbital melanoma. Arch Opthalmol 1978; 96: 2255-2258.

11 Loeffler KU, Witschel H. Primary malignant melanoma of the orbit arising in a cellular blue naevus. $\mathrm{Br} J$ Ophthalmol 1989; 73: 388-393.

12 Shields JA, Shields CL, Eagle RC, De Potter P, Oliver GL. Necrotic orbital melanoma arising de novo. $\mathrm{Br} J$ Ophthalmol 1993; 77: 187-189.

13 Dutton JJ, Anderson RL, Schelper RL et al. Orbital malignant melanoma and oculodermal melanocytosis. Ophthalmology 1984; 91: 497-507.

14 Gunduz K, Shields JA, Shields CL, Eagle RC. Periorbital cellular blue nevus leading to orbitopalpebral and intracranial melanoma. Ophthalmology 1998; 105: 20462050.

15 Jay B. Malignant melanoma of the orbit in a case of oculodermal melanosis (naevus of Ota). Br J Opthalmol 1965; 49: 359-363.

16 Rice CD, Bron HH. Primary orbital melanoma associated with orbital melanocytosis. Arch Ophthalmol 1990; 108: 1130-1134.

17 Rottino A, Kelly AS. Primary orbital melanoma. Case report and review of the literature. Arch Ophthalmol 1942; 27: 949. 